\title{
Surveillance of Above- and Below-Ground Mosquito Breeding Habitats in a Rural Midwestern Community: Baseline Data for Larvicidal Control Measures Against West Nile Virus Vectors
}

\author{
Tamara A. Kronenwetter-Koepel, BS; Jennifer K. Meece, PhD; Christopher A. Miller; and Kurt D. Reed, MD
}

\begin{abstract}
Background Mosquitoes in the genus Culex are thought to play a major role as vectors in the transmission cycle of West Nile virus (WNV) and other arboviruses in the United States. Effective control of mosquitoes through larviciding and adulticiding is expensive for communities and should be guided by reliable surveillance data on the distribution of mosquito breeding habitats. However, few small to medium sized cities in rural areas of the midwestern United States have this type of baseline information available.
\end{abstract}

Objective During the summer of 2004, we investigated the characteristics of Culex and other mosquito-breeding habitats in a rural centralWisconsin community with a population of approximately 19,000. Such baseline information will aid in the development of rational strategies to control mosquito populations and prevent human exposure to WNV and other mosquito-transmitted viruses.

Methods Mosquito larvae were collected and identified weekly from 14 below-ground storm water catch basins and 10 above-ground standing water sites distributed throughout the community. Collection began June 4, 2004 and continued through September 24, 2004. For each collection site the primary and adjacent land use patterns were determined.

Results Over the study period, I,244 larvae were collected from catch basins; $94 \%$ were Culex species. Breeding activity was first detected in early July. Peak breeding was observed during a period of several weeks when average daily temperatures were at the maximum observed and rainfall had declined. Organically enriched catch basins in low intensity urban sites adjacent to forests and wetlands were found to be more productive breeding habitats compared to catch basins having little organic debris located in isolated high intensity urban sites. Above-ground standing water sites produced I,504 larvae; $66 \%$ of which were Culex species. Flood control ditches and permanent wetlands with stagnant water were most productive, while ditches with moving water were least productive habitats. Larvae were produced earlier in the season by above-ground sites than were produced by catch basins. However, larvae production was more variable in above-ground sites since half the sites became dry at some point during the study period.

Conclusion The observed differences in Culex larvae production based on the variables of habitat-type, temperature, and precipitation support the need for ongoing surveillance in communities to guide public health officials in planning for and prioritizing mosquito control efforts.

Keywords: Mosquito control; Breeding; Environment; West Nile virus; Culex

Reprint Requests: Jennifer K. Meece, PhD, Clinical Research Center, Marshfield Clinic Research Foundation, 1000 North Oak Avenue, Marshfield, WI 54449, Telephone: 7I5-387-9376, Fax: 7I5-389-33I9, Email: meece.jennifer@mcrf.mfldclin.edu
Received: December 3, 2004

Revised: December 23, 2004

Accepted: December 28, 2004 


\section{$\mathrm{M}$}

osquitoes present a significant threat to public health because they serve as vectors for numerous infectious agents that are pathogenic for humans and animals. In the United States, West Nile virus (WNV) has emerged as the most prevalent mosquito-borne infection, with over 9,800 human cases documented in 2003. ${ }^{1}$ In the western hemisphere, WNV is endemic across most of the United States, as well as southern Canada, Mexico, and parts of the Caribbean. ${ }^{2,3}$

WNV is maintained in nature by enzootic transmission cycles between wild birds and mosquitoes. ${ }^{4}$ Previous research has shown that virus levels are not amplified to the same degree in all bird species, and mosquito species can vary greatly in their competence as efficient vectors. ${ }^{5-11}$ In the eastern United States, two closely related mosquito species, Culex pipiens and Culex restuans, have been implicated as being among the most important WNV vectors. Both species have adapted well to urban areas and are strongly ornithophilic (bird loving) in their feeding preferences. ${ }^{8-11}$ Studies have demonstrated that some populations of Culex pipiens may exhibit a more generalized feeding behavior and may take blood meals from humans as well. ${ }^{12-14}$ In the western United States, Culex tarsalis is believed to be one of the most important vectors for transmission of $\mathrm{WNV}^{6}$

In general, humans and other mammals are not thought to contribute substantially to the overall transmission cycle of WNV in nature. However, they can become infected after being bitten by infected mosquitoes. Fortunately, most human infections with WNV are asymptomatic or mild, but severe cases of meningoencephalitis do occur and are associated with significant morbidity and mortality. ${ }^{4,15,16}$ Since an effective vaccine for WNV in humans is not yet available, current strategies to prevent or limit cases have focused on reducing mosquito numbers in endemic areas.

Mosquito control interventions, such as larviciding and adulticiding, are expensive and are most effective in preventing WNV when they target those mosquito species that are abundant, highly competent to transmit virus, and feed on both birds and humans. ${ }^{17,18}$ There are over 2,500 different mosquito species worldwide, at least 200 species in the United States, and at least 50 species in Wisconsin. ${ }^{19,20}$ In some communities, there may be a lack of data on the distribution and relative abundance of many mosquito species. In other communities, mosquito control districts have been functioning for a number of years to control pest mosquitoes; in such districts there is often baseline data on mosquito diversity and abundance going back decades. This background information can make it much easier to develop rational strategies to control Culex populations and prevent human exposure to WNV and other mosquito-borne viruses. Unfortunately, mosquito control districts are usually in larger urban areas, and many small- to medium-sized cities and rural areas lack baseline data on Culex and other mosquito habitats. This study was conducted to determine the distribution and breeding cycles of Culex and other mosquitoes in Marshfield, Wisconsin, a community of 18,908 located in central Wisconsin and representative of many rural midwestern cities.

\section{Materials and Methods}

\section{Study site}

The city of Marshfield, Wisconsin is located in central Wisconsin (coordinates $44^{\circ} 40^{\prime} 08^{\prime \prime} \mathrm{N}, 090^{\circ} 10^{\prime} 18^{\prime \prime} \mathrm{W}$ ). The city encompasses 13.4 square miles and has a population of 18,908 based on the year 2000 census data. There are 135 miles of paved streets and 69 miles of storm sewers that collect water from curbs and gutters. In some residential areas there are ditch drainage systems present in lieu of curb and gutters (Turchi $\mathrm{T}$, personal communication).

\section{Climate}

Daily precipitation and average daily temperatures at the Marshfield Municipal Airport were obtained from the National Oceanic and Atmospheric Administration's National Climate Data Center. ${ }^{21}$

\section{Surveillance}

Larval mosquitoes were collected 1 time per week in 14 storm water catch basins (below-ground sites) from June 18, 2004 through September 24, 2004 (15 weeks), and in 10 above-ground standing water sites from June 4, 2004 through September 24, 2004 (17 weeks). Catch basin sites were selected based on a grid system with sampling occurring approximately every mile within the city limits (figure 1). One catch basin collection event resulted in approximately 4 to 5 liters of water from 2 catch basins at each site per visit. A hand-pumped siphon was used to transfer water directly from the catch basin into the collection container.

Above-ground standing water sites were selected using a wetland inventory map and visual observation of potential breeding sites (figure 1). Larvae were collected using a 350 $\mathrm{ml}$ mosquito dipper. One collection event equaled 10 dips per visit, per site. Surveillance of all sites was discontinued following the first frost of the season.

\section{Site classification}

Below-ground catch basins are concrete reservoirs located below storm water grates (figure 2). These basins function to collect debris washed from city streets during rainfall. Storm water enters via a grate and a pipe system with debris being collected in the basin to avoid obstructing the storm water system. The sites in the current study were characterized by the above-ground habitat immediately surrounding the catch basin representing the primary habitat and the above-ground habitat(s) within a radius of 0.1 mile of the catch basin representing the adjacent habitat. Habitats were classified using WISCLAND land cover habitat classifications. ${ }^{22}$ Catch basin habitat classifications included: 
- low intensity urban: $<50 \%$ solid impervious land cover of human-made materials with some interspersed vegetation;

- high intensity urban: $>50 \%$ solid impervious land cover of human-made materials;

- forest: an upland area of land covered with woody perennial plants;

- wetland: naturally occurring area inundated with water.

Above-ground standing water sites were characterized by the immediate habitat and by water movement at the site. Water movement was categorized as either stagnant or moving. Habitat classifications included:

- flood-control drainage ditches: above-ground artificial habitats created to handle excess rainfall;

- permanent wetlands: naturally occurring areas inundated with water on a permanent basis and containing mixed vegetation;

- temporal woodland ponds: naturally occurring areas in hardwood forests in which water occurs on a temporary basis;

- temporal wetlands: naturally occurring areas inundated with water on a temporary basis containing mixed vegetation.

\section{Mosquito identification}

Larvae and adult mosquitoes were identified to the species level using standard morphological taxonomic keys. ${ }^{19,23}$ Mosquito larvae collected from catch basins were identified immediately or stored in ethanol until identification was made in cases where damage to the larvae occurred due to the harsh pumping of the collection method. Pupae were grown in an incubator at $25^{\circ} \mathrm{C}$ and reared to adults for identification. Larvae and pupae collected from above-ground sites were incubated at $25^{\circ} \mathrm{C}$ and reared to adults for identification.

\section{Results}

\section{Climate}

Temperatures averaged $64.0^{\circ} \mathrm{F}$ during the study period. The driest portion of the study period, July 9 through July 30, 2004, coincided with the warmest average temperatures over the study period (figure 3). Precipitation was variable throughout the study period. However, higher amounts of rainfall typified the first 6 weeks of collection, followed by a 3 -week dry period and intermittent rainfall occurring during the remaining 8 weeks of collection.

\section{Surveillance}

In total, we collected 1,244 larvae from catch basins, representing 4 genera and 9 species (table 1). Of all larvae and pupae collected from catch basins, 94\% were Culex spp. Evidence of mosquito breeding activity in catch basins was not observed until the first week of July (figure 4). The Culex spp. population peaked at 406 larvae collected during the week of July 16, 2004. During this 3-week dry period, prefaced by 4 weeks of extensive rainfall, the average daily

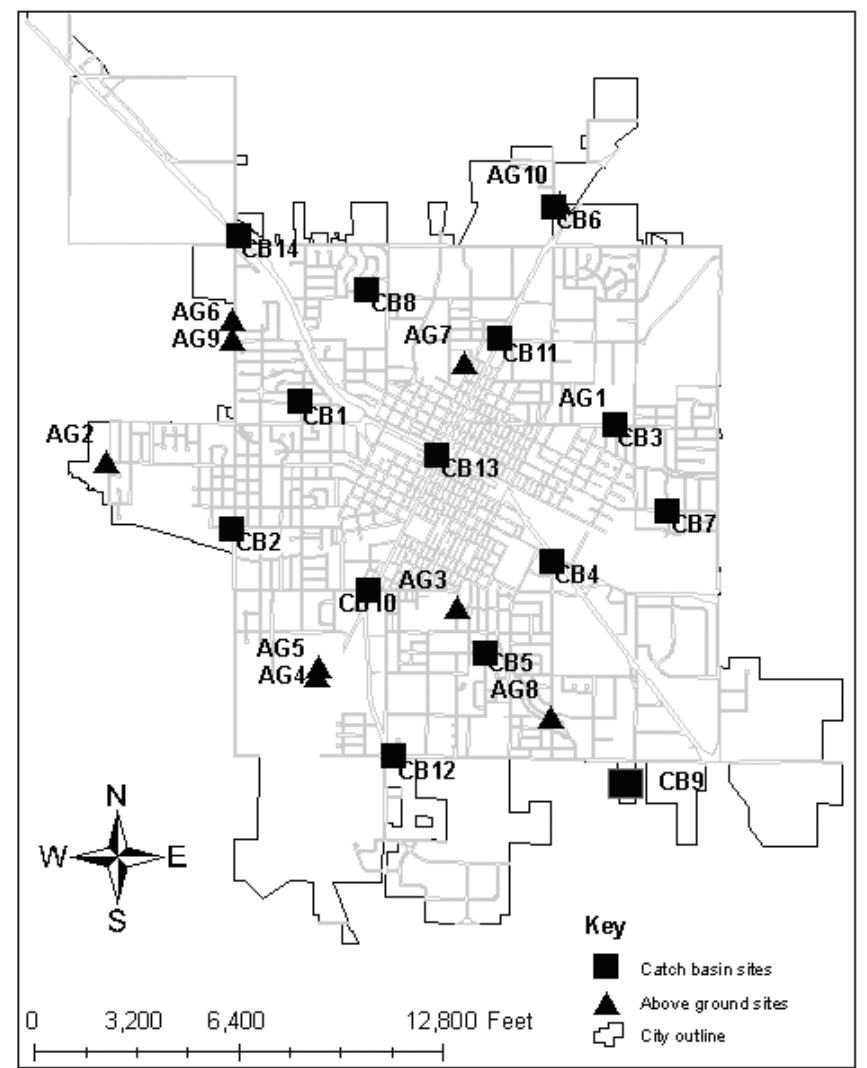

Figure 1. Mosquito larva collection sites in Marshfield, Wisconsin. The location of the below-ground storm water catch basin collection sites are shown with squares and the above-ground standing water sites with triangles. Catch basin sites are distributed along a grid at approximately 1-mile intervals starting from the geographic center of the city (CB13). The location of above-ground standing water sites is less uniform because they represent a combination of human-made and natural habitats.

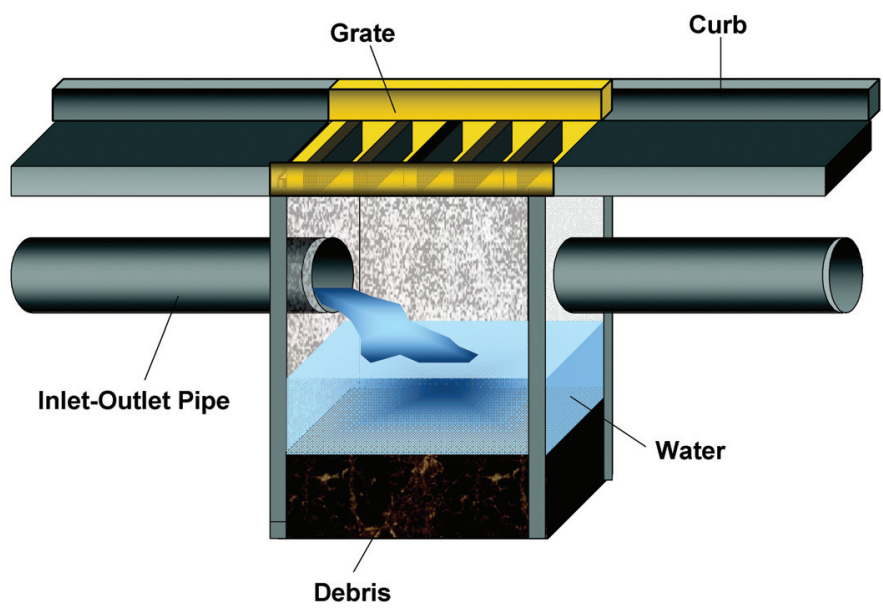

Figure 2. Illustration of a storm water catch basin. Storm water carrying debris and organic material flows from above-ground into the grate. Debris settles and excess water is carried out. Water below the inlet/outlet pipe remains in the catch basin. Catch basins often retain water even during dry periods. 


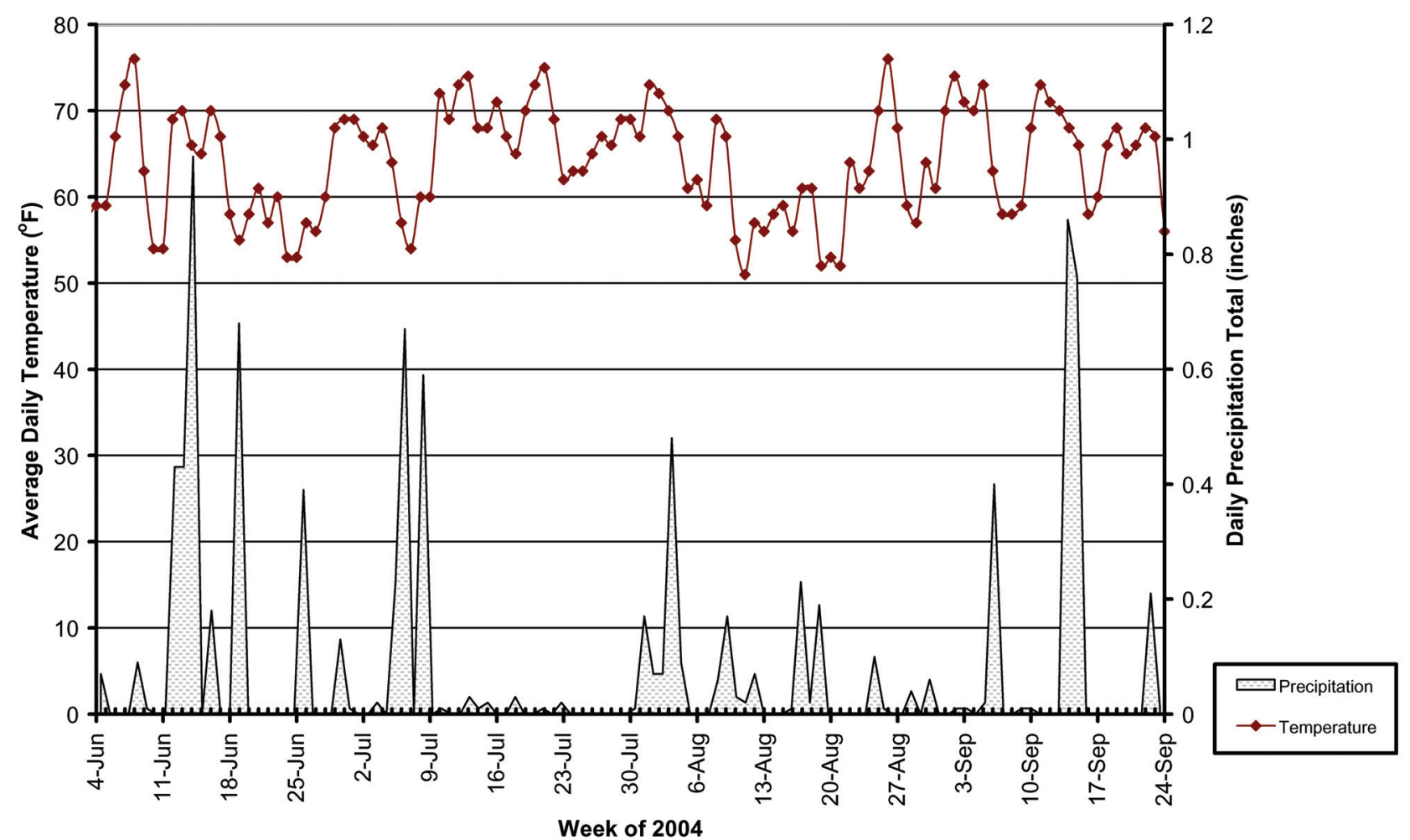

Figure 3. Average daily temperatures and daily precipitation amounts from June 4, 2004 through September 24, 2004.

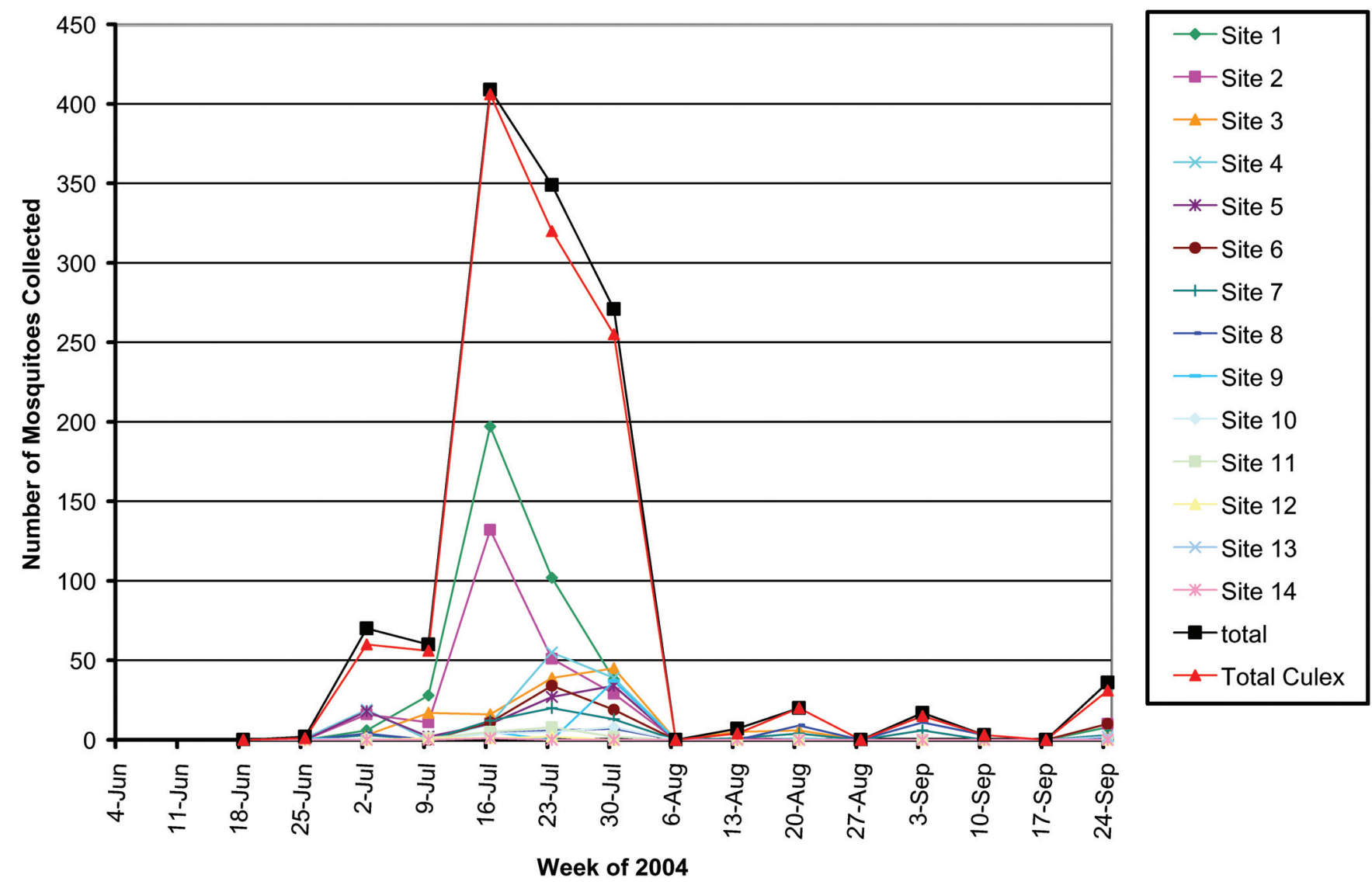

Figure 4. Mosquitoes collected by week from storm water catch basin sites. 
Table 1. Total number of larvae collected by genus and species. ${ }^{*}$

\begin{tabular}{|c|c|c|c|}
\hline \multirow[b]{2}{*}{ Genus } & \multirow[b]{2}{*}{ Species } & \multicolumn{2}{|c|}{ Number larvae collected } \\
\hline & & Catch basin & Above ground \\
\hline \multirow[t]{7}{*}{ Culex } & pipiens & 160 & 278 \\
\hline & restuans & 970 & 606 \\
\hline & salinarius & 3 & 8 \\
\hline & tarsalis & 8 & 38 \\
\hline & territans & 0 & 20 \\
\hline & Unidentifiable & 30 & 37 \\
\hline & Total & 1171 & 987 \\
\hline \multirow[t]{3}{*}{ Culiseta } & inornata & 3 & 121 \\
\hline & morsitans & 0 & 2 \\
\hline & Total & 3 & 123 \\
\hline \multirow[t]{8}{*}{ Aedes/Ochlerotatus } & excrucians & 0 & 4 \\
\hline & canadensis & 0 & 1 \\
\hline & punctor & 2 & 0 \\
\hline & spencerii & 1 & 8 \\
\hline & trivittatus & 1 & 1 \\
\hline & vexans & 0 & 69 \\
\hline & Unidentifiable & 3 & 4 \\
\hline & Total & 7 & 87 \\
\hline \multirow[t]{2}{*}{ Orthopodomyia } & alba & 1 & 0 \\
\hline & Total & 1 & 0 \\
\hline \multirow[t]{4}{*}{ Anopheles } & barberi & 0 & 1 \\
\hline & punctipennis & 0 & 29 \\
\hline & Unidentifiable & 0 & 1 \\
\hline & Total & 0 & 31 \\
\hline Maleł & & 10 & 256 \\
\hline Unidentifiable & & 52 & 20 \\
\hline Total larvae & & 1244 & 1504 \\
\hline
\end{tabular}

* Total number of mosquitoes collected from storm water catch basins and above-ground standing water sites.

¥ Collected larvae were raised to adults allowing identification of males.

temperature reached $71^{\circ} \mathrm{F}$. From all the catch basin sites that supported mosquito development, the highest number of mosquito larvae was observed during the 1-month period of July 2 through July 30, 2004. Productivity from all the sites dramatically decreased after July 30, 2004.

Each catch basin site was categorized by the immediate habitat in which the site was located as well as by the adjacent habitat(s). Site-specific habitat classifications and the number of collected mosquito larvae are shown in table 2. A strong relationship was observed between immediate and adjacent habitat and the ability of the catch basin to support mosquito development. In general, the catch basin sites in low intensity urban areas surrounded by forests and/or wetlands were the most productive. Catch basins located in and surrounded by high intensity urban areas supported the fewest developing mosquitoes. At catch basin site 1, a single Orthopodomyia alba larvae was collected; a species that has not previously been documented in Wisconsin.

In the above-ground sites we collected 1,504 larvae representing 4 genera and 14 species (table 1). Of larvae and pupae collected from above-ground sites, $66 \%$ were Culex spp. Evidence for mosquito breeding was found as early as the first week of collection and remained relatively consistent, with several peak-breeding periods throughout the 17-week study period (figure 5). It is important to note that the initial peak in mosquito numbers during the first 4 
Table 2. Catch basin mosquito collections by site and habitat.

\begin{tabular}{|c|c|c|c|c|}
\hline Site & Primary habitat & Adjacent habitat & Total \# collected & \# of Culex \\
\hline 1 & Low intensity urban & Forest & 379 & 368 \\
\hline 2 & Low intensity urban & Forest and wetland & 249 & 232 \\
\hline 3 & Low intensity urban & Forest and wetland & 133 & 118 \\
\hline 4 & Low intensity urban & High intensity urban and forest & 125 & 116 \\
\hline 5 & Low intensity urban & Low intensity urban & 92 & 88 \\
\hline 6 & High intensity urban & Wetland & 74 & 71 \\
\hline 7 & Low intensity urban & Forest & 62 & 56 \\
\hline 8 & Low intensity urban & Low intensity urban & 45 & 42 \\
\hline 9 & High intensity urban & Wetland & 43 & 41 \\
\hline 10 & High intensity urban & High intensity urban & 18 & 18 \\
\hline 11 & High intensity urban & High intensity urban & 16 & 13 \\
\hline 12 & High intensity urban & High intensity urban & 4 & 2 \\
\hline 13 & High intensity urban & High intensity urban & 3 & 3 \\
\hline 14 & High intensity urban & High intensity urban & 1 & 1 \\
\hline
\end{tabular}

Low intensity urban: $<50 \%$ solid impervious land cover of human-made materials with some interspersed vegetation. High intensity urban: $>50 \%$ solid impervious land cover of human-made materials. Forest: an upland area of land covered with woody perennial plants. Wetland: naturally occurring area inundated with water. Culex: Culex spp.

\begin{tabular}{lcllccc}
\hline \multicolumn{2}{l}{ Table 3. Above-ground } & mosquito collections by site and habitat. \\
\hline Site & $\begin{array}{c}\text { \# of Weeks } \\
\text { sampled }\end{array}$ & Habitat & $\begin{array}{l}\text { Water } \\
\text { movement }\end{array}$ & $\begin{array}{c}\text { Total \# } \\
\text { collected }\end{array}$ & $\begin{array}{c}\text { \# of } \\
\text { Culex }\end{array}$ & $\begin{array}{c}\text { \# of } \\
\text { Ae./Oc. }\end{array}$ \\
\hline 1 & 4 & Flood control drainage ditch & Stagnant & 767 & 598 & 0 \\
2 & 17 & Permanent wetland & Stagnant & 366 & 198 & 0 \\
3 & 15 & Flood control drainage ditch & Stagnant & 200 & 150 & 0 \\
4 & 7 & Temporal woodland pond & Stagnant & 83 & 15 & 45 \\
5 & 6 & Temporal woodland pond & Stagnant & 28 & 0 & 18 \\
6 & 17 & Flood control drainage ditch & Moving & 27 & 16 & 0 \\
7 & 17 & Flood control drainage ditch & Moving & 16 & 11 & 0 \\
8 & 17 & Flood control drainage ditch & Moving & 13 & 1 & 0 \\
9 & 17 & Flood control drainage ditch & Moving & 3 & 0 & 0 \\
10 & 4 & Temporal wetland & Stagnant & 1 & 0 & 0
\end{tabular}

Flood control drainage ditch: above ground artificial habitats created to handle excess rainfall. Permanent wetland: naturally occurring areas inundated with water on a permanent basis and containing mixed vegetation. Temporal wetland: naturally occurring areas inundated with water on a temporary basis containing mixed vegetation. Temporal woodland pond: naturally occurring areas in hardwood forests in which water occurs on a temporary basis. Culex: Culex spp.; Ae./Oc.: Aedes/Ochlerotatus spp. 


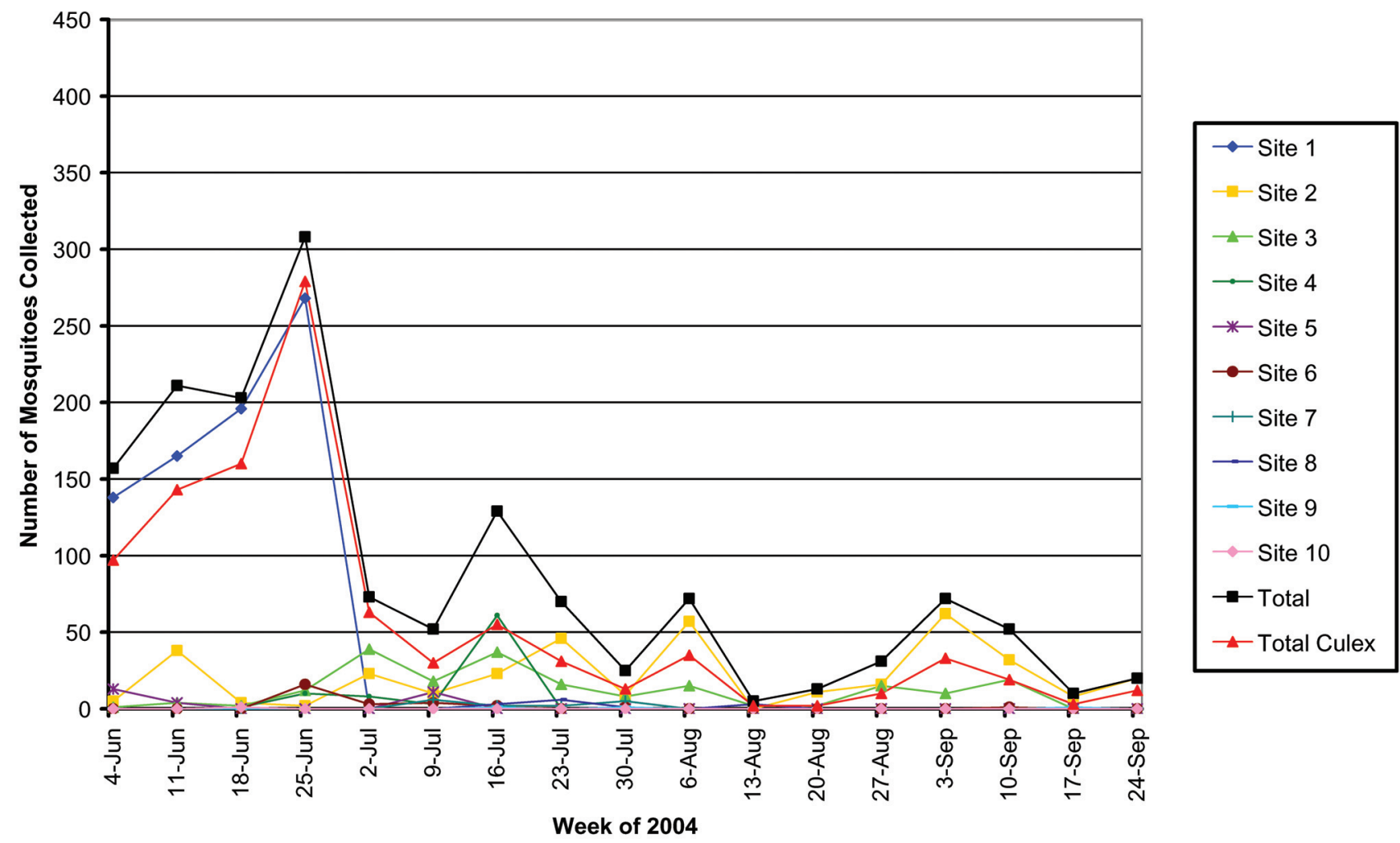

Figure 5. Mosquitoes collected by week from above-ground standing water sites.

weeks of collection were primarily attributable to site 1 . This site consisted of a small, shallow, rock-lined drainage ditch approximately 4 feet by 8 feet containing stagnant water. It was sampled for only 4 weeks before it was destroyed by city construction, yet it supported more developing mosquitoes than any other above ground sites with a total of 767 mosquitoes, 598 of which were Culex spp., including Culex tarsalis. Of the remaining collection locations, sites 2 and 3 contributed $77 \%$ of all mosquitoes collected. Overall, mosquito populations peaked during the week of July 16, 2004 with a total of 129 mosquitoes.

Table 3 shows the habitat type and the movement of water within the collection site used to categorize each above-ground site. Total number of mosquitoes collected and the total number of Culex spp. are also shown. A strong relationship between water movement and the ability of a site to support mosquito development was observed. The above ground sites supporting the highest number of developing mosquitoes were human-made flood-control drainage ditches and permanent wetlands with stagnant water. Those supporting the fewest developing mosquitoes were flood-control drainage ditches with moving water. The Culex spp. was found infrequently in wooded areas with temporal stagnant ponds (e.g., sites 4 and 5). This environment favored Aedes/Ochlerotatus species by greater than 4:1. Additionally, only 5 out of 10 sites maintained water throughout the study period.

\section{Discussion}

Comprehensive mosquito surveillance provides the basis for rational mosquito prevention and control strategies by public health and government officials. ${ }^{17}$ Surveillance has become increasingly important since the introduction of WNV into North America in $1999 .{ }^{24}$ For many mid-sized municipalities, where mosquito control programs currently are lacking, there is little data available to form sound prevention and control strategies. Effective mosquito control intervention requires knowledge of the timing of mosquito breeding activity and breeding site preferences. The purpose of this study was to compile a baseline data set, from June through September of 2004, of the breeding cycles and site preferences of Culex and other mosquitoes in Marshfield, Wisconsin, a typical, mid-sized midwestern city.

Mosquito control can occur at two action levels and should be selected based upon the objectives of the control program. ${ }^{18}$ In the first action level, the prevention targets immature mosquitoes (larvae) in aquatic habitats. The objective of a larval control program (larviciding) would be to target specific habitats for mosquito species that may be involved in the transmission of disease. ${ }^{17}$ An excellent example of this is targeted larviciding of storm water catch basins for Culex spp. mosquitoes. A variety of treatments are available for controlling mosquito larvae including chemical insecticides, growth hormone regulators, and the application of bacteria toxic to invertebrate organisms. Each of these materials has advantages and disadvantages and each should 
be considered carefully based upon the goals and objectives of the mosquito control program. The materials in each control option have different half-lives and recommended dosages; therefore, the timing of application should be based upon the timing of the emergence of targeted mosquito species. Mosquito control aimed at larvae eliminates mosquitoes before they are injurious to humans or animals. Targeted larviciding is often a more favorable approach, as it is less environmentally damaging to treat selected areas and is more cost effective than spraying for adult mosquitoes. ${ }^{17,18,25,26}$

In the second action level, adult mosquitoes are eliminated by application of aerosolized chemical insecticides sprayed into the air (adulticiding). Adult mosquito control targets mosquitoes when they are potentially injurious to humans and animals. ${ }^{18}$ This form of control is often implemented to control biting, pest mosquitoes when their numbers have reached unacceptable levels, or when clusters of human or veterinary mosquito-transmitted diseases have been identified. When disease clusters are identified, mosquitoes represent the direct link to human and veterinary risk and, at this point, reduction of that risk is best accomplished by adult mosquito control efforts. However, application of these insecticides into the environment may result in negative public perception due to its aerial application and higher associated costs. ${ }^{17,25,26}$

In this study, storm water catch basins provided an excellent environment for supporting the development of Culex mosquitoes. These environments are subterranean, cool, and contain organically enriched water sources for mosquitoes to lay eggs. During extended dry periods, catch basins may be one of the few available breeding sites for Culex mosquitoes. This phenomenon was observed in our study as only 5 of 10 above-ground standing water sites maintained water throughout the study period. Many of the Culex spp., such as Culex pipiens and Culex restuans, prefer laying eggs in organically enriched water. During the larval mosquito surveillance conducted, all 14 catch basins supported the development of mosquito larvae, although to differing levels. Catch basins located in low intensity urban areas surrounded by forests, wetlands, and low intensity urban habitats supported the greatest number of mosquito larvae. Catch basins in high intensity urban areas supported the least number of mosquito larvae. There are several possible explanations for these observations. We observed that the catch basins in low intensity urban areas contained more organic debris (e.g., leaves, grass clippings) than those in the high intensity urban areas. In low intensity urban areas with adjacent forests or wetlands, adult female mosquitoes would have more available blood meal sources (e.g., greater abundance of birds and small mammals) and areas that support vegetation for mosquitoes to rest during the hottest, driest times of the day. Finally, catch basins in the high intensity urban areas may have a higher volume of water flowing into them because there is more impervious surface area and less lawn and other green space to absorb water resulting in more rigorous flushing of the basins during rainfall.
Mosquitoes developing in the catch basins in the study area were not detected until the first week of July. If a mosquito control program were to be implemented in this municipality, careful consideration should be given to the type of larvicide and its timing of release. For example, methoprene, the growth hormone regulator packaged under the commercial name Altosid (Wellmark International, Schaumburg, IL), has applications that last either 30 days or 120 to 150 days. In our study area, mosquitoes were detected in catch basins from July 2, 2004 until the study was completed on September 24, 2004. In this instance, one application that lasts 120 to 150 days may be the most appropriate control. The precise timing of mosquito breeding in catch basins may vary from year-to-year and effective control measures may require adjustment based upon rainfall, temperature, and other environmental factors. Ongoing surveillance is important for understanding and modeling the complex ecological variables that modulate mosquito breeding. The unexpected finding of Orthopodomyia alba exemplifies the paucity of mosquito surveillance data in Wisconsin. This is not likely a species new to Wisconsin, but rather one that has not been identified previously through any comprehensive mosquito surveillance program.

The above-ground standing water sites surveyed during this study were highly variable in their ability to sustain breeding mosquitoes. The most important characteristic that predicted the presence or absence of mosquitoes developing in these aquatic systems was water movement. Those systems where water was moving, even during dry periods, were the least able to support mosquito development. One of the most productive standing water sites was destroyed after just 4 weeks of sampling. This site, characterized as a flood-control drainage ditch with stagnant water, was supporting the development of Culex spp. when other sites were not yet doing so. This site was a rock-lined ditch, approximately 4 feet by 8 feet with no vegetation providing shade or cover. Although we did not determine water temperature for any site, we hypothesize the water at this site was warmer than the others during June and was able to support the development of mosquitoes earlier in sampling.

Overall, Culex mosquitoes at 7 of 10 sites dominated the above-ground standing water site collections. The Culex spp. comprised $66 \%$ of the total larval collection. Culex tarsalis, whose range is thought to be typically located west of the Mississippi River and who is considered to be among the most efficient vectors of WNV, was identified at several of our surveillance sites. 6,19 Given the importance of Culex tarsalis as a vector of WNV, its presence in our study area is an important finding. Overall, the Aedes/Ochlerotatus species was found in relatively low numbers throughout the surveillance area. Two sites (4 and 5), both temporal woodland ponds, supported the highest number of Aedes/Ochlerotatus mosquitoes. Many Aedes/Ochlerotatus mosquitoes preferentially breed in flood plains, riparian wetlands, emergent wetlands, temporal wetlands, and temporal 
woodland ponds with little water movement. The eggs of many Aedes/Ochlerotatus species can lay dormant for years during dry periods and be revived when habitats are flooded. ${ }^{18}$

Public perception of what constitutes a good location for mosquito breeding and development is often different from what surveillance data show. Therefore, implementing effective surveillance and control strategies is greatly enhanced by close collaboration among scientists, public health and other government officials, and the public. For many communities, advancements in Geographic Information Systems (GIS) can make planning and implementing mosquito control measures much more efficient. For example, satellite images and orthotopic photographs are readily available for characterizing land use patterns as an aid in identifying wetlands and other potential above ground breeding sites. In addition, many cities have GIS data files that pinpoint the location of catch basins and other human-made structures. Census tract data can be used to identify concentrations of highly susceptible populations, such as the elderly, within a community. These data layers can be overlaid to produce maps highlighting specific areas within communities that are the highest priority for intervention. Information of this type has practical value to local governments at a time when budgets are tight and resources must be allocated where they will provide the greatest good. This study contains data from one mosquito breeding season. Data must be collected in future seasons to determine whether the trends we observed will be consistent with annual temperature and precipitation fluctuations.

\section{Acknowledgments}

The authors wish to thank Marshfield Clinic Research Foundation and its Summer Research Internship in Biomedical Sciences program, Dr. Ray Haselby, and anonymous philanthropic donors for support of this project. We thank Terra Jenson, Kimberly Bliven, and David Reed for their assistance with field collections. We are also grateful to Mr. Thomas Turchi and Mr. Eric Spangenberg, of the city of Marshfield for supplying technical information regarding the engineering design of the city of Marshfield, as well as maps used to identify collection sites. The authors do not necessarily endorse products mentioned in this manuscript.

\section{References}

1. Centers for Disease Control and Prevention Web site. Division of Vector-Borne Diseases - West Nile virus. Available at: http://www.cdc.gov/ncidod/dvbid/westnile/index.htm. Accessed November 30, 2004.

2. United States Geological Survey Web site. West Nile virus maps. Available at: http://westnilemaps.usgs.gov/. Accessed November 30, 2004.

3. Canadian Cooperative Wildlife Health Center Web site. Canada maps: West Nile virus bird surveillance. Available at: http://wildlife.usask.ca/WestNileAlertHTML/WestNIleAlert2 003ENG.htm. Accessed August 26, 2003.

4. Campbell GL, Marfin AA, Lanciotti RS, Gubler DJ. West Nile virus. Lancet Infect Dis 2002;2:519-529.
5. Allison AB, Mead DG, Gibbs SE, Hoffman DM, Stallknecht DE. West Nile virus viremia in wild rock pigeons. Emerg Infect Dis [serial on the Internet]. 2004 Dec [cited 2004 Dec 2]. Available at http://www.cdc.gov/ncidod/EID/vol10no12/04-0511.htm.

6. Goddard LB, Roth AE, Reisen WK, Scott TW. Vector competence of California mosquitoes for West Nile virus. Emerg Infect Dis 2002;8:1385-1391.

7. Komar N, Langevin S, Hinten S, Nemeth N, Edwards E, Hettler D, Davis B, Bowen R, Bunning M. Experimental infection of North American birds with the New York 1999 strain of West Nile virus. Emerg Infect Dis 2003;9:311-322.

8. Turell MJ, Sardelis MR, Dohm DJ, O'Guinn ML. Potential North American vectors of West Nile virus. Ann N Y Acad Sci 2001;951:317-324

9. Turell MJ, O’Guinn ML, Dohm DJ, Jones JW. Vector competence of North American mosquitoes (Diptera: Culicidae) for West Nile virus. J Med Entomol 2001;38:130134.

10. Turell MJ, Sardelis MR, O’Guinn ML, Dohm DJ. Potential vectors of West Nile virus in North America. Curr Top Microbiol Immunol 2002;267:241-252.

11. Sardelis MR, Turell MJ, Dohm DJ, O'Guinn ML. Vector competence of selected North American Culex and Coquillettidia mosquitoes for West Nile virus. Emerg Infect Dis 2001;7:1018-1022.

12. Spielman A. Structure and seasonality of nearctic Culex pipiens populations. Ann N Y Acad Sci 2001;951:220-234.

13. Fonseca DM, Keyghobadi N, Malcolm CA, Mehmet C, Schaffner F, Mogi M, Fleischer RC, Wilkerson RC. Emerging vectors in the Culex pipiens complex. Science 2004;303:1535-1538.

14. Apperson CS, Hassan HK, Harrison BA, Savage HM, Aspen SE, Farajollahi A, Crans W, Daniels TJ, Falco RC, Benedict M, Anderson M, McMillen L, Unnasch TR. Host feeding patterns of established mosquito vectors of West Nile virus in the eastern United States. Vector Borne Zoonotic Dis 2004:4:71-82.

15. Komar N. West Nile viral encephalitis. Rev Sci Tech 2000;19:166-176.

16. Petersen LR, Marfin AA. West Nile virus: a primer for the clinician. Ann Intern Med 2002;137:173-179.

17. Centers for Disease Control and Prevention Web site. Epidemic/epizootic West Nile virus in the United States: Revised guidelines for surveillance, prevention and control. Available at: http://www.cdc.gov/ncidod/dvbid/westnile/resources/wnvguidelines-apr-2001.pdf. Accessed August 2003.

18. Olkowski W. Larval control of mosquitoes. Common Sense Pest Control XVII(2) Spring 2001;8-18.

19. Darsie RF Jr, Ward RA. Identification and geographical distribution of the mosquitoes of North America, north of Mexico. Mosq Syst 1981;1:1-313.

20. Meece JK, Henkel JS, Glaser L, Reed KD. Mosquito surveillance of West Nile virus in southeastern Wisconsin2002. Clinical Medicine \& Research 2002;1:37-42.

21. National Climatic Data Center Web site. NOAA satellites and information. Available at: http://lwf.ncdc.noaa.gov/oa/climate/stationlocator.html. Accessed December 2, 2004.

22. Wisconsin Department of Natural Resources Web site. Landcover data (WISCLAND). Available at: http://www.dnr.state.wi.us/maps/gis/datalandcover.html. Accessed May 12, 2004.

23. Siverly RE. Mosquitoes of Indiana. Indianapolis (IN): Indiana State Board of Health; 1972. Available at: http://wrbu.si.edu/www/REF1/122890-2.PDF. Accessed December 29, 2004. 
24. Lanciotti RS, Roehrig JT, Deubel V, Smith J, Parker M, Steele K, Crise B, Volpe KE, Crabtree MB, Scherret JH, Hall RA, MacKenzie JS, Cropp CB, Panigrahy B, Ostlund E, Schmitt B, Malkinson M, Banet C, Weissman J, Komar N, Savage HM, Stone W, McNamara T, Gubler DJ. Origin of the West Nile virus responsible for an outbreak of encephalitis in the northeastern United States. Science 1999;17:2333-2337.

25. Thier A. Balancing the risks: vector control and pesticide use in response to emerging illness. J Urban Health 2001;78:372-381.

26. Gubler DJ, Campbell GL, Nasci R, Komar N, Petersen L, Roehrig JT. West Nile virus in the United States: guidelines for detection, prevention, and control. Viral Immunol 2000;13:469-475.

\section{Author Affiliations}

Tamara A. Kronenwetter-Koepel, BS; Jennifer K. Meece, PhD, Christopher A. Miller; Clinical Research Center, Marshfield Clinic Research Foundation, 1000 N. Oak Avenue,

Marshfield, Wisconsin 54449.

Kurt D. Reed, MD, Clinical Research Center, Marshfield Clinic Research Foundation and Microbiology Section, Marshfield Laboratories, Marshfield Clinic, 1000 N. Oak Avenue, Marshfield, Wisconsin 54449. 